\title{
A REGULAÇÃO DE AVARIA GROSSA E A ATUAÇÃO DO TRIBUNAL MARÍTIMO
}

\section{THE REGULATION OF GROSS AVARAGE AND THE PERFORMANCE OF THE MARITIME COURT}

Recebido: 04.06.2017

Aprovado: 28.08.2017

Ingrid Zanella Andrade Campos*

RESUMO: Este artigo tem como objetivo demonstrar o papel do Tribunal Marítimo no procedimento especial de regulação de avaria grossa, instituído pelo Código de Processo Civil, instituído pela Lei $\mathrm{n}^{\circ}$ 13.105, de 16 de março de 2015, em seu Capítulo XII, artigos 707 a 711. A problemática cinge-se a identificar até que ponto pode existir a atuação do Tribunal Marítimo na regulação de avaria grossa. Na desenvoltura do trabalho se destaca a importância da atuação dos meios alternativos, visando uma solução tempestiva e adequada a determinadas questões envolvendo direitos altamente técnicos e especializados, como o Direito Marítimo. Para tanto serão tratados o conceito e modalidades de avarias marítimas, bem como a atuação do Tribunal Marítimo, e o procedimento especial de regulação de avaria grossa.

Palavras-chave: Regulação deavariagrossa. Tribunal marítimo. Incidentes da navegação.

\begin{abstract}
This article aims to demonstrate the role of the Maritime Court in the special procedure of general average adjustment imposed by the Civil Procedure Code, established by Law 13,105, of March 16, 2015, in Chapter XII, articles 707 to 711 . The problem to identify even-gird that point there may be the performance of the Maritime Court in the general average adjustment. The resourcefulness of the work highlights the importance of the role of the alternative media, targeting a timely and appropriate solution to certain issues involving highly technical and specialized rights, such as the Maritime Law. To do so will be treated the concept and modalities of maritime damage and the activities of the Maritime Court, and the special procedure of general average adjustment.
\end{abstract}

Keywords: General average adjustment. Maritime court. Incidents of navigation.

\footnotetext{
* Professora do Programa de Pós-Graduação em Direito da Faculdade Damas da Instrução Cristã. Doutora e Mestre pela Direito na Universidade Federal de Pernambuco (UFPE). Professora Adjunta da Universidade Federal de Pernambuco (UFPE). Auditora Ambiental Líder. Perita Ambiental Judicial. Coordenadora e Professora da Pós-Graduação em Direito Marítimo, Portuário e do Petróleo da UNINASSAU/PE. Professora da especializações em Direito Marítimo, Portuário e Ambiental da UNISANTOS/SP, Faculdade de Direito de Vitória/ES, UNIVALI/SC e UFRN. Presidente da Comissão de Direito Marítimo, Portuário e do Petróleo da OAB/PE. Membro da Comissão de Meio Ambiente da OAB/ PE. Oficial do Conselho da Ordem do Mérito Naval/Marinha do Brasil. Advogada no escritório Zanella Advogados \& Consultores (<www.zanellaconsultoria.adv.br>). E-mail: < ingrid@zanellaconsultoria.adv.br >.
} 


\section{INTRODUÇÃO}

No que concerne à navegação, a Constituição da República Federativa do Brasil de 1988, através da Emenda Constitucional nº 7 , de 15 de agosto de 1995 deu nova redação ao parágrafo único, do artigo $178^{1}$, que passou a permitir o uso de bandeiras estrangeiras na navegação de cabotagem no Brasil, desde que afretadas por empresas brasileiras, o que possibilitou a abertura constitucional à navegação interior por embarcações estrangeiras.

Assim, com a introdução da navegação rompia-se a barreira da economia regional, a quantidade de mercadorias a serem transportadas por via marítima aumentou, significativamente. Ocorreu a internacionalização da economia, com a abertura de fronteiras comerciais, através dos portos (PORTO, 2006, p. 49).

Considerando o franco crescimento das atividades marítimas, da mesma forma houve um aumento de acidentes marítimos, demonstrando a importância da consecução dessa atividade econômica em plena harmonia com as normas da Constituição Federal e demais legislação aplicável a esse setor produtivo, possibilitando uma responsabilização ampla e eficaz.

Este artigo busca demonstrar que o papel do Tribunal Marítimo no procedimento especial de regulação de avaria grossa, instituído pelo Código de Processo Civil, instituído pela Lei n 13.105, de 16 de março de 2015, em seu Capítulo XII, artigos 707 a 711.

A referida atuação demonstra a importância de que solução dos conflitos deve ser percebida através de uma concepção heteroprodutiva (TEUBNER, 1989), envolvendo cortes não integrantes do Poder Judiciário, onde já se defende a aplicação, através da lex mercatoria, de um direito transnacional comercial, que é independente de qualquer legislação nacional (TEUBNER, 1997).

O CPC/2015 está em consonância com essa interpretação, visto que já incluiu taxativamente a determinação de suspensão do processo judicial quando se discutir em juízo questão decorrente de acidentes e fatos da navegação de competência do Tribunal Marítimo (Art. 313, VII).

Nessa ordem, os meios alternativos de pacificação social estão se somando à atuação do Poder Judiciário, como é o caso do Tribunal Marítimo, corte altamente especializada. Neste cenário mundial, as cortes estatais de justiça não são os únicos foros para a resolução dos conflitos e para a busca da satisfação de pretensões resistidas ou insatisfeitas, especialmente pela circunstância dos elevados custos e da demora da prestação da tutela jurisdicional oferecida pelo Estado-juiz, dentre outros entraves.

Francesco Carnelutti defende a ideia de equivalentes jurisdicionais, na medida em que certos atos, embora não determinados pelo interesse estatal de composição de conflitos, contam com o reconhecimento de serem dotados de idoneidade para alcançar o mesmo escopo ao qual tende a jurisdição (CARNELUTTI, 1936, p. 154). Por sua vez, para Athos Gusmão, os meios alternativos são os equivalentes jurisdicionais que, embora não

1 Dessa forma o parágrafo único do artigor78, da Constituição Federal, passou a ter a seguinte redação: "Na ordenação do transporte aquático, a lei estabelecerá as condições em que o transporte de mercadorias na cabotagem e a navegação interior poderão ser feitos por embarcações estrangeiras”. 
provenientes de autoridade judiciária, findam por conduzir ao mesmo resultado, ou seja, a composição definitiva da lide (CARNEIRO, 2001, p. 45).

Portanto, a problemática do presente artigo cinge-se a identificar até que ponto pode existir a atuação do Tribunal Marítimo na regulação de avaria grossa, como esse processo administrativo próprio surgiria e se haveria prejuízo às demais formas de responsabilidade.

Inicialmente será preciso explicitar o conceito e modalidades de avarias marítimas, bem como a atuação do Tribunal Marítimo e o procedimento especial de regulação de avaria grossa.

O artigo fora elaborado seguindo o método dedutivo, partindo-se das premissas até a conclusão. A constatação da veracidade das premissas permite atestar, pelos encadeamentos lógicos realizados com argumentos condicionais, a verdade da conclusão.

\section{AVARIAS MARÍTIMAS}

O Código Comercial Brasileiro (Lei $\mathrm{n}^{\circ} 556$, de 20 de junho de 1850 ) conceitua avaria como "todas as despesas extraordinárias feitas a bem do navio ou da carga, conjunta ou separadamente, bem como todos os danos acontecidos àquele ou a esta, desde o embarque e partida até a sua volta e desembarque" (Art. 761).

Desta forma, o Direito Marítimo a palavra avaria significa despesas ou danos extraordinários concernentes ao navio e/ou à carga.

É sabido que a doutrina aponta diversas formas de classificação das avarias, por exemplo, quanto à natureza: dano ou despesa; ou quanto à causa: simples ou grossa (Art. 763, Código Comercial).

As avarias-danos abarcam os prejuízos matérias e imateriais, decorrentes da inutilizarão ou estrago da coisa ou da redução do valor. Já as avarias-despesas se consubstanciam em desembolsos de caráter excepcionais necessários para que seja completada a expedição marítima.

As avarias simples ou particulares derivam de vício próprio do navio e/ou da carga, de fatos da tripulação, do transportador ou do armador. Não é produzida intencionalmente pelos envolvidos com o objetivo de evitar um dano ou prejuízo maior.

Destaca-se, desde já, que a avaria simples acarretará uma demanda judicial que seguirá um procedimento comum, pois o valor é suportado pela parte que deu causa ao incidente marítimo, assim se discutirá a responsabilidade civil.

Os requisitos para caracterização da avaria simples são: existência de perigo real e eminente e a ausência de vontade/intenção dos envolvidos na aventura marítima.

Destaca-se que Código Comercial (Lei $\mathrm{n}^{\circ}$ 556/1850) apresenta um rol exemplificativo de avarias simples e particulares, no art. 766 , da seguinte forma:

1 - O dano acontecido às fazendas por borrasca, presa, naufrágio, ou encalhe fortuito, durante a viagem, e as despesas feitas para as salvar.

2 - A perda de cabos, amarras, âncoras, velas e mastros, causada por borrasca ou outro acidente do mar.

3 - As despesas de reclamação, sendo o navio e fazendas reclamadas 
separadamente.

4 - O conserto particular de vasilhas, e as despesas feitas para conservar os efeitos avariados.

5 - O aumento de frete e despesa de carga e descarga; quando declarado o navio inavegável, as fazendas são levadas ao lugar do destino por um ou mais navios (artigo no. 614).

Em geral, as despesas feita; e o dano sofrido só pelo navio, ou só pela carga, durante o tempo dos riscos.

Já a avaria grossa ocorre nas hipóteses de danos ou despesas extraordinários decorrentes de um ato intencional e razoavelmente praticado em defesa dos interesses da comunidade marítima, em uma situação de perigo real e iminente, buscando resultado útil.

Da mesma forma, o Código Comercial (Lei $\mathrm{n}^{\circ}$ 556/1850) apresenta um rol exemplificativo de avarias grossas, no artigo 764 , qual seja:

1 - Tudo o que se dá ao inimigo, corsário ou pirata por composição ou a título de resgate do navio e fazendas, conjunta ou separadamente

2 - As coisas alijadas para salvação comum.

3 - Os cabos, mastros, velas e outros quaisquer aparelhos deliberadamente cortados, ou partidos por força de vela para salvação do navio e carga.

4 - As âncoras, amarras e quaisquer outras coisas abandonadas para salvamento ou benefício comum.

5 - Os danos causados pelo alijamento às fazendas restantes a bordo.

6 - Os danos feitos deliberantemente ao navio para facilitar a evacuação d'água e os danos acontecidos por esta ocasião à carga.

7 - O tratamento, curativo, sustento e indenizações da gente da tripulação ferida ou mutilada defendendo o navio.

8 - A indenização ou resgate da gente da tripulação mandada ao mar ou à terra em serviço do navio e da carga, e nessa ocasião aprisionada ou retida.

9 - As soldadas e sustento da tripulação durante arribada forçada.

10 - Os direitos de pilotagem, e outros de entrada e saída num porto de arribada forçada.

11 - Os aluguéis de armazéns em que se depositem, em, porto de arribada forçada, as fazendas que não puderem continuar a bordo durante o conserto do navio.

12 - As despesas da reclamação do navio e carga feitas conjuntamente pelo capitão numa só instância, e o sustento e soldadas da gente da tripulação durante a mesma reclamação, uma vez que o navio e carga sejam relaxados e restituídos. 13 - Os gastos de descarga, e salários para aliviar o navio e entrar numa barra ou porto, quando o navio é obrigado a fazê-lo por borrasca, ou perseguição de inimigo, e os danos acontecidos às fazendas pela descarga e recarga do navio em perigo.

14 - Os danos acontecidos ao corpo e quilha do navio, que premeditadamente se faz varar para prevenir perda total, ou presa do inimigo.

15 - As despesas feitas para pôr a nado o navio encalhado, e toda a recompensa por serviços extraordinários feitos para prevenir a sua perda total, ou presa.

16 - As perdas ou danos sobrevindos às fazendas carregadas em barcas ou lanchas, em consequência de perigo.

17 - As soldadas e sustento da tripulação, se o navio depois da viagem começada é obrigado a suspendê-la por ordem de potência estrangeira, ou por superveniência de guerra; e isto por todo o tempo que o navio e carga forem impedidos. 18 - O prêmio do empréstimo a risco, tomado para fazer face a despesas que 
devam entrar na regra de avaria grossa.

19 - O prêmio do seguro das despesas de avaria grossa, e as perdas sofridas na venda da parte da carga no porto de arribada forçada para fazer face às mesmas despesas.

20 - As custas judiciais para regular as avarias, e fazer a repartição das avarias grossas.

21 - As despesas de uma quarentena extraordinária.

Portanto, para que seja configurada a avaria grossa é preciso satisfazer os seguintes requisitos:

\footnotetext{
1. dano ou despesa extraordinária, intencional e razoavelmente cometidos para preservar os bens envolvidos na expedição marítima;

2. ser plena e efetiva;

3. ter sido praticada de forma intencional e voluntária, decorrente da vontade humana;

4. existência de perigo real e iminente (o receio, ainda que justo, não possibilita a caracterização);

5. benefício ou resultado útil em prol de todos os envolvidos na viagem marítima;

6. ausência de responsabilidade prévia do transportador marítimo.
}

A avaria grossa, de acordo com o Código Comercial (art. 762), será regida pelo que estabelecer a carta partida ou o conhecimento de embarque e, na falta dessa previsão, pelo Código Comercial.

Destaca-se que internacionalmente as Regras de York e Antuérpia (RYA) constam na maioria dos contratos de transporte marítimo. De acordo com as RYA, haverá um ato de avaria grossa quando, e somente quando, qualquer sacrifício e/ou despesa extraordinários for intencional e razoavelmente efetuado ou incorrido para a segurança comum, com o propósito de preservar de perigo a propriedade envolvida em uma aventura marítima comum.

Desta forma, de acordo com a Regra "Paramount" (preponderante), em nenhuma hipótese haverá qualquer admissão por sacrifício ou despesa, a menos que razoavelmente feitos ou incorridos (In no case shall there be any allowance for sacrifice or expenditure unless reasonably made or incurred). Assim a razoabilidade do ato é elemento intrínseco caracterizador da avaria grossa pela RYA.

$\mathrm{Na}$ ocorrência de avaria grossa, as despesas decorrentes serão suportadas proporcionalmente por todos os interessados na expedição marítima. Assim, haverá uma parcial exoneração da responsabilidade do transportador marítimo, pois os prejuízos/ danos serão repartidos entre os interessados, essencialmente os responsáveis pelo navio (proprietário e armador), pelo frete (afretador) e pela carga.

Considerando que na avaria grossa deve haver uma repartição dos prejuízos, torna-se necessário que haja a atuação de um perito, que pode ser livremente escolhida pelas partes, que ateste se tratar se avaria grossa e montante que caberá a cada parte assumir. Caso não haja consenso de quem atuará como perito, instaurar-se-á, então, o procedimento especial de regulação de avaria grossa, conforme disposto no CPC/2015. 


\section{DO PROCEDIMENTO ESPECIAL DE AVARIA GROSSA}

Como visto, no caso de avaria grossa poderá haver o procedimento especial de regulação quando não existir consenso entre os interessados em quem deva atuar como regulador de avaria.

O Código Comercial (Lei $\mathrm{n}^{\circ} 556 / 1850$ ), no art. 783, determina que a regulação, repartição ou rateio das avarias grossas serão feitos por árbitros, nomeados por ambas as partes. Assim, havendo consenso entre as partes, não há que se falar em procedimento especial, pois o regulador será escolhido livremente e haverá apenas um procedimento extrajudicial.

Mesmo o Código Comercial já prgevendo a regulação da avaria grossa, a jurisprudência do Supremo Tribunal Federal (STF) entendia pela desnecessidade de regulação, vide:

STF - RE: 57591 SP DJ 09-05-1969 RTJ VOL-50331- PP. Ementa. AVARIA GROSSA. CARACTERIZAÇÃO. RATEIRO DAS DESPESAS EXTRAORDINARIAS. DESNECESSIDADE DE REGULAÇÃO PARA CONFIGURAÇÃO DA AVARIA. RECURSOS EXTRAORDINÁRIOS NÃO CONHECIDOS.

Supremo Tribunal Federal. $1^{\underline{a}}$ Turma. Título RE 57591 / SP - SÃO PAULO. 04/03/1969 Ementa. AVARIA GROSSA. CARACTERIZAÇÃO. RATEIRO DAS DESPESAS EXTRAORDINARIAS. DESNECESSIDADE DE REGULAÇÃO PARA CONFIGURAÇÃO DA AVARIA. RECURSOS EXTRAORDINÁRIOS NÃO CONHECIDOS.

Neste sentido, disciplina o $\mathrm{CPC} / 2015$, que quando inexistir consenso acerca da nomeação de um regulador de avarias, o juiz de direito da comarca do primeiro porto onde o navio houver chegado, provocado por qualquer parte interessada, nomeará um de notório conhecimento (art. 707).

Assim, o procedimento especial pode ser instaurado por qualquer parte interessada, com o objetivo de comprovar a existência de avaria grossa, bem como para apurar a extensão do dano e a devida proporção de responsabilidade. O procedimento especial possibilitará que haja a identificação da responsabilidade de cada parte envolvida na aventura marítima, a exata contribuição para que, posteriormente, possa ser prestada a devida caução, cujo valor, se houver discordância, será arbitrado pelo juiz.

Destaca-se que existindo consenso entre os interessados quanto à escolha de um regulador de avaria a regulação será feita extrajudicialmente. Portanto, procedimento é especifico para a regulação da avaria grossa, pois em caso de ocorrência de avaria simples apenas haverá demanda judicial afeta à responsabilidade civil do transportador marítimo.

O procedimento especial para confirmar a ocorrência de avaria grossa é de competência da Justiça Estadual, no foro da comarca do primeiro porto onde o navio tiver atracado após a ocorrência da avaria.

Nesse sentido, o Código Comercial (Lei n ${ }^{\circ} 556 / 1850$ ) estabelece, no art. 786, que a regulação e a repartição das avarias grossas deverá fazer-se no porto da entrega da carga. Todavia, quando por dano acontecido depois da saída, o navio for obrigado a regressar ao 
porto da carga, as despesas necessárias para reparar os prejuízos da avaria grossa podem ser neste ajustadas. Ainda, o art. 787, do referido Código, estabelece que as avarias grossas ou comuns serão liquidadas no porto da entrega da carga.

A primeira tarefa do regular é declarar, de forma justificada, se o caso pode ser caracterizado como avaria grossa, ou seja, se os danos são passíveis de rateio na forma de avaria grossa, para posteriormente, exigir das partes envolvidas a apresentação de garantias idôneas para que possam ser liberadas as cargas aos consignatários (vide art. 708, CPC/2015).

Desta forma, o regulador deve realizar um exame prévio do caso com o objetivo de declarar, justificadamente, se o caso pode ser caracterizado como avaria grossa, bem como se os danos e despesas são passíveis de rateio entre os envolvidos. Após a declaração pelo regulador de que o caso é de avaria grossa, caberá ao juiz exigir das partes a apresentação de garantias idôneas para que possam ser liberadas as cargas aos consignatários.

As partes envolvidas na aventura marítima, e que serão responsabilizadas pela recomposição do dano/despesa decorrente da avaria grossa, devem apresentar documentos necessários à regulação da avaria grossa, tanto prova documental, como outras provas admitidas em juízo, por quaisquer meios, desde que lícitas e moralmente legítimas.

Disciplina o Código Comercial (Lei oㅜ 556, de 25 de junho de 1850), art. 504, que no livro denominado Diário da Navegação se assentarão diariamente, enquanto o navio se achar em algum porto, os trabalhos que tiverem lugar a bordo e os consertos ou reparos do navio. No mesmo livro se assentaram também todas as ocorrências interessantes à navegação, acontecimentos extraordinários que possam ter lugar a bordo, como os danos ou avarias que o navio ou a carga possam sofrer, as deliberações que se tomarem por acordo dos oficiais da embarcação e os competentes protestos.

Igualmente, Código Comercial (Lei no 556, de 25 de junho de 1850) estabelece que todos os processos testemunháveis e protestos formados a bordo, tendentes a comprovar sinistros, avarias, ou quaisquer perdas, devem ser ratificados com juramento do capitão perante a autoridade competente (Juiz de Direito, art. 766 do CPC) do primeiro lugar onde chegar (art. 505 do Código Comercial).

Desta forma, o procedimento especial da regulação da avaria grossa ou comum pode ser precedido de ratificação de protesto marítimo ou de processo testemunhável formado a bordo, procedimento previsto nos artigos 766 a 770 do CPC/2015.

O Código Comercial Brasileiro dispõe acerca do direito de o capitão exigir, antes de abrir as escotilhas do navio, que os consignatários da carga prestem fiança idônea ao pagamento da avaria grossa, cujas respectivas mercadorias forem obrigadas ao rateio da contribuição comum, a fim de fazer frente ao pagamento da contribuição da avaria grossa, a que seus bens forem obrigados ao rateio final. Recusando-se os consignatários a prestar a fiança exigida, pode, inclusive, o capitão requerer o depósito judicial dos efeitos obrigados à contribuição, até ser pago, ficando o preço da venda sub-rogado, para se efetuar por ele o pagamento da avaria grossa, logo que o rateio tiver lugar (arts. 784 e 785).

Assim que a declaração de avaria grossa for apresentada pelo regulador, o juiz deve determinar a intimação dos interessados, estabelecendo prazo para impugnação. As partes poderão impugnar a declaração de avaria grossa em duas hipóteses: quando 
discordarem do regulador designado pelo juiz ou quando entenderem que o caso não se coaduna como avaria grossa.

Após a declaração, o regulador deverá apresentar o regulamento da avaria grossa, que deverá contar a extensão do dano/despesa e a exata proporção das despensas que devem ser assumida pelas partes envolvidas.

O prazo para que o regulador apresente o regulamento é até doze meses, contado da data da juntada dos documentos nos autos pelas partes, podendo o prazo ser ampliado a critério do juiz. As partes terão vistas aos autos pelo prazo comum de 15 dias, podendo oferecer impugnação. Após as vistas pelas partes, é possibilitada a impugnação do referido regulamento. Em caso de sentença homologatória ou que rejeite a impugnação acatando os termos do regulamento apresentado pelo regulador, considerando que tenha havido a caução, o depósito ou a contribuição provisória, é, assim, passível de execução. Segundo o Código Comercial (Lei $n^{\circ}$ 556/1850), art. 793, a sentença que homologa à repartição das avarias grossas com condenação de cada um dos contribuintes tem força definitiva, e pode ser executada logo, ainda que dela se recorra.

Ao regulador de avarias aplicam-se as disposições, no que couber, afetas ao perito, considerando que na regulação da avaria grossa será imprescindível profissional que possua conhecimento técnico ou científico. O regulador será, dessa forma, nomeado pelo juiz entre os profissionais legalmente habilitados e os órgãos técnicos ou científicos devidamente inscritos em cadastro mantido pelo tribunal ao qual o juiz está vinculado.

O regulador de avarias, como o perito, atuará como um auxiliar da Justiça, e, por

esta razão, devem incidir sobre esse as causas de impedimento e de suspeição. Assim, o perito pode escusar-se ou ser recusado por impedimento ou suspeição, cabendo às partes tal arguição.

Destaca-se que não é facultado às partes escolher, de comum acordo, o perito, pois se as partes estiverem de comum acordo quanto à escolha do regulador de avaria grossa, a regulação será realizada extrajudicialmente. Como visto, o procedimento judicial apenas correrá quando inexistir consenso acerca da nomeação de um regulador de avarias grossa.

Da mesma forma o juiz não poderá dispensar prova pericial quando as partes, na inicial e na contestação, apresentarem sobre as questões de fato pareceres técnicos ou documentos elucidativos que considerar suficientes, pois a atuação do regulador é obrigatória no procedimento judicial de regulação de avaria grossa.

Após a explanação no que concerne à avaria grossa e seu procedimento judicial de regulação, torna-se necessário demonstrar como o Tribunal Marítimo, poderá atuar, como será abordado a seguir.

\section{DA RESPONSABILIDADE ADMINISTRATIVA MARÍTIMA}

Destaca-se que há dois tipos de processos marítimos, quais sejam: o que tramita no Tribunal Marítimo, a seguir analisado, e o da Capitania dos Portos e Costas. No que concerne atuação deste órgão em atos afetos ao meio ambiente, a doutrina e a jurisprudência se posicionam de forma pacifica, isso em decorrência de existir previsão 
legal nesse sentido, o que não ocorre com a atuação do Tribunal Marítimo, objeto central deste artigo.

Evidencia-sea Lei no 9.537/1997, que dispõe sobrea segurança do tráfego aquaviário em águas sob jurisdição nacional, determina que cabe à autoridade marítima promover a implementação e a execução desta Lei, com o propósito de assegurar a salvaguarda da vida humana e a segurança da navegação, e a prevenção da poluição ambiental por parte de embarcações, plataformas ou suas instalações de apoio.

Por sua vez, o Tribunal Marítimo se consubstancia como órgão de atuação administrativa, não integrante do Poder Judiciário, sendo disciplinado pela Lei ${ }^{\circ}{ }^{2.180}$, de 05 de fevereiro de 1954, que estabelece ser, o referido Tribunal, órgão, autônomo, auxiliar do Poder Judiciário, com atribuições de julgar os acidentes e fatos da navegação marítima, fluvial e lacustre e as questões relacionadas com tal atividade, e com jurisdição em todo o território nacional. O Tribunal Marítimo é formado por sete juízes civis e militares, com jurisdição em todo o território nacional (CAMPOS, 2001, p. 179).

De acordo com Eliane Octaviano Martins, apesar de se consubstanciar em um órgão administrativo, o Tribunal Marítimo não exerce exclusivamente funções administrativas, mas também, atividades judicantes (MARTINS, 2008, p. 122).

Igualmente, a jurisdição do Tribunal Marítimo se estende sobre todo o território nacional e alcança toda pessoa jurídica ou física envolvida, por qualquer força ou motivo, em acidentes ou fatos da navegação, respeitados os demais instrumentos de Direito Interno e as normas do Direito Internacional (CAMPOS, 2001, p. 103).

Dessa forma, a jurisdição desse tribunal pode ser contenciosa e voluntária. No que tange à jurisdição voluntária o Tribunal Marítimo atuará na seara administrativa de expediente, como por exemplo, com expedição de certidões. Já na jurisdição contenciosa a corte marítima em comento atua como órgão julgador dos acidentes marítimos e fatos da navegação, onde se destacam o processo administrativo punitivo e processo administrativo disciplinar.

Destarte, a competência e jurisdição de maior relevância é a de julgar os acidentes e fatos da navegação, como estabelece a Lei $\mathrm{n}^{\circ}$ 2.180/1954, em seu artigo 13 (treze), determinando as especificidades de cada caso, as circunstâncias, e até aplicando penas previstas na mesma legislação.

A teor do artigo 13, inciso I da referida lei, ao julgar os acidentes efatos da navegação, elencados de forma exemplificativa nos artigos 14 e 15 da referida lei, o Tribunal Marítimo deverá definir a natureza, determinando as causas, circunstâncias e extensão, bem como indicar os seus responsáveis.

A Lei $\mathrm{n}^{\circ}$ 2.180/1954 não define o que seriam os acidentes da navegação, apenas os exemplificam, em seu artigo 14, da seguinte forma: naufrágio, encalhe, colisão, abalroação, água aberta, explosão, incêndio, varação, arribada e alijamento; avaria ou defeito nas instalações do navio, que ponha em risco a embarcação, as vidas e fazendas de bordo.

Por sua vez, a supra citada Lei, em seu art. 15, menciona que se consideram fatos da navegação: o mau aparelhamento ou a impropriedade da embarcação para o serviço 
em que é utilizada, e a deficiência da equipagem; a alteração da rota; a má estimação da carga, que sujeite a risco a segurança da expedição; a recusa injustificada de socorro a embarcação em perigo; todos os fatos que prejudiquem ou ponham em risco a incolumidade e segurança da embarcação, as vidas e fazendas de bordo; e o emprego da embarcação, no todo ou em parte, na prática de atos ilícitos, previstos em lei como crime ou contravenção penal, ou lesivos à Fazenda Nacional.

No mesmo sentido, a Convenção Montego Bay (CNUDM), Decreto n 1.530, de 22 de junho de 1995, no artigo 221, ao tratar das medidas para evitar poluição ambiental resultante de acidentes marítimos, entende que acidente marítimo significa um abalroamento, encalhe ou outro incidente de navegação ou acontecimento a bordo de uma embarcação ou no seu exterior, de que resultem danos materiais ou ameaça iminente de danos materiais à embarcação ou à sua carga.

Comovisto, que a Lei $\mathrm{n}^{\circ} \mathbf{2 . 1 8 0 / 1 9 5 4}$ institui um rol exemplificativo com tipificações genéricas, o que pode ampliar a competência do Tribunal Marítimo. Portanto, a competência do Tribunal Marítimo é julgar os acidentes e os fatos, não apenas os descritos na Lei ${ }^{\circ}$ 2.180/1954.

A interpretação de que o rol de competência do TM é exemplificativo foi inclusive objeto de apreciação pelo TM, no julgamento do Processo no 27.050/2012, que envolveu o caso da plataforma "SEDCO 706" CHEVRON BRASIL LTDA. Igualmente, o Código Comercial Brasileiro (Lei no 556 , de 25 de junho de 1850) regula os fatos da navegação no Título IX, do naufrágio e salvamento, Título X, das arribadas forçadas, Título XI, do dano causado por abalroação, Título XII, do abandono, e, por fim, no Título XIII, das avarias.

Nesse sentido o voto do mencionado Juiz do Tribunal Marítimo entendeu que:

Como se não bastassem os fortíssimos argumentos anteriores, se fixássemos nosso raciocínio apenas na letra da lei, a poluição continuaria sendo considerada como acidente da navegação. Se não vejamos: o art. 14, “a” e "b" da Lei n.2.18o \54 previu o alijamento e a avaria das fazendas como acidentes da navegação. Ora, por exemplo, o derramamento de milhares de litros de óleo elou demais produtos transportados não configura alijamento ou avaria na carga? É perfeitamente possível que toda a carga do navio seja avariada, configurando acidente da navegação, que, nada mais é que poluição. Como cabe ao Tribunal Marítimo julgar o acidente da navegação, determinando sua natureza, extensão, causas e responsáveis, configurada a competência do Tribunal para o julgamento da poluição, mais uma vez. Inclusive esse foi o posicionamento doutrinário defendido com brilhantismo pela Dra. Ingrid Zanella, especialista na matéria, no III Workshop do Tribunal Marítimo, recentemente realizado.

Portanto, resta entendido que a competência do Tribunal Marítimo é julgar os acidentes e os fatos, não apenas os descritos na Lei ${ }^{\circ} \mathbf{2 . 1 8 0} / 1954$, considerando o referido diploma legal estabelecer um rol meramente exemplificativo².

2 Inclusive, este entendimento foi exposto pioneiramente no III WorkShop do Tribunal Marítimo "Em busca de uma maior difusão do Direito Marítimo", com a palestra : "O Papel do Tribunal Marítimo na Defesa do Meio Ambiente" ministrada em 09/10/2013” (CAMPOS ZANELLA, 2013). 


\section{O TRIBUNAL MARÍTIMO E A REGULAÇÃO DE AVARIA GROSSA}

Acredita-se que regulação de avaria grossa encontra ligação direta com o Tribunal Marítimo, principalmente, no que concerne ao afastamento de elementos / requisitos impensáveis ao reconhecimento da avaria grossa.

Inicialmente, de acordo com o art. 17, alínea f, da Lei ${ }^{\circ}$ 2.180/1954, na apuração da responsabilidade por fatos e acidentes da navegação, cabe ao Tribunal Marítimo investigar os requisitos que autorizam a regulação estão presentes, nos casos de acidentes ou fato da navegação de que possa resultar a classificação de danos e despesas como avaria grossa ou comum.

Destaca-se quea referida hipótese legal nunca foi aplicada pelo Tribunal Marítimo. Entretanto, de acordo com o dispositivo legal retro, mesmo o regulador devendo atuar como perito, sendo indicado pelo juiz, quando inexistir consenso entre as partes, a lei especifica do Tribunal Marítimo determina que quando a avaria grossa resultar de acidente ou fato da navegação, caberá àquele Tribunal determinar se existem no caso concreto os elementos necessários para a configuração da avaria grossa e possibilitar que haja o rateio entre as partes envolvidas.

Caso a referida possibilidade fosse aventada pelo Tribunal Marítimo, haveria uma atuação ainda mais incisiva do Tribunal Marítimo, pois caberia a ele determinar se a avaria pode ser considerada como grossa, independentemente da vontade das partes.

Desta forma, o Tribunal Marítimo executaria a primeira tarefa do regular, qual seja de declarar, de forma justificada, se o caso pode ser caracterizado como avaria grossa, ou seja, se os danos são passíveis de rateio na forma de avaria grossa (vide Art. 708, CPC/2015).

Por quanto, é atribuição do Tribunal Marítimo, de acordo com o art. 13, Lei $\mathrm{n}^{\circ}$ 2.180/1954, julgar os acidentes e fatos da navegação definindo-lhes a natureza e determinando-lhes as causas, circunstâncias e extensão, ou seja, poderá o referido tribunal identificar se há no caso os requisitos que autorizam a regulação nos casos de acidentes ou fato da navegação de que possa resultar a classificação de danos e despesas como avaria grossa ou comum. Como visto, essa é a primeira tarefa do regulador, qual seja: declarar justificadamente se os danos são passíveis de rateio na forma de avaria grossa.

Entretanto, não poderá o Tribunal Marítimo ficar responsável pela elaboração do regulamento de avaria, que envolve a repartição financeira dos custos e prejuízos, devendo, portanto, este procedimento ser realizado pelo regulador especifico, como prevê o art. 710, CPC/15 (O regulador apresentará o regulamento da avaria grossa no prazo de até 12 (doze) meses, contado da data da entrega dos documentos nos autos pelas partes, podendo o prazo ser estendido a critério do juiz).

Assim, mesmo que o referido tribunal reconhecesse e identificasse os requisitos que autorizam a regulação de avaria grossa nos casos de acidentes ou fato da navegação de que possa resultar a classificação de danos e despesas como avaria grossa ou comum, ainda haveria, no Poder Judiciário o procedimento especial de regulação de avaria grossa.

Entretanto, considerando que inexiste, até o momento, atuação do Tribunal 


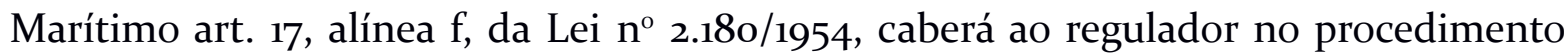
especial de avaria grossa desempenhar todos as tarefas instituídas no CPC.

A segunda, e mais importante, atuação do Tribunal Marítimo relacionada à avaria grossa éa possibilidade de descaracterização da razoabilidade da conduta do comandante em face da condenação por fatos e acidentes da navegação, quando restar configurada a culpa.

Como visto, para que seja configurada a avaria grossa é preciso satisfazer os seguintes requisitos:

\footnotetext{
1. dano ou despesa extraordinária, intencional e razoavelmente cometidos para preservar os bens envolvidos na expedição marítima;

2. ser plena e efetiva;

3. ter sido praticada de forma intencional e voluntária, decorrente da vontade humana;

4. existência de perigo real e iminente;

5. benefício ou resultado útil em prol de todos os envolvidos na viagem marítima;

6. ausência de responsabilidade prévia do transportador marítimo.
}

Destaca-se que a responsabilidade administrativa marítima segue a teoria da responsabilidade subjetiva, não havendo espaço para responsabilidade objetiva, devendo-se perquirir o dolo ou a culpa. A responsabilidade administrativa subjetiva pressupõe a existência concomitante de dano, nexo causal e dolo ou culpa.

Neste sentido preceitua o Art. 186, do Código Civil, vide: "Aquele que, por ação ou omissão voluntária, negligência ou imprudência, violar direito e causar dano a outrem, ainda que exclusivamente moral, comete ato ilícito.".

De acordo com a Lei n ${ }^{0}$ 2180/1954, art. 17, “a”, na apuração da responsabilidade por fatos e acidentes da navegação, cabe ao Tribunal Marítimo investigar se o capitão, o prático, o oficial de quarto, outros membros da tripulação ou quaisquer outras pessoas foram os causadores por dolo ou culpa. Desta forma, a responsabilidade administrativa marítima está pautada no reconhecimento da culpa.

Conforme é possível se depreender dos acórdãos abaixo citados para que haja condenação, sempre haverá a caracterização dos elementos caracterizadores da responsabilidade subjetiva, entre esses destaca-se a culpa, vide:

TRIBUNALMARÍTIMO. PROCESSO № 25.713/11ACÓRDÃO. N/M“WESTFALIA EXPRESS”. Encalhe de mercante estrangeiro durante navegação no canal de acesso ao Terminal de Contêineres - TECON, porto do Rio de Janeiro, baía de Guanabara, Município do Rio de Janeiro, RJ. Sem danos ao mercante e, sem registros de acidentes pessoais ou de poluição ao meio ambiente hídrico. Erro de navegação. Condenação. ACORDAM os Juízes do Tribunal Marítimo, por unanimidade quanto ao mérito e por maioria quanto à pena dos representados, nos termos do voto da Exma. Sra. Juíza-Relatora: a) quanto à natureza e extensão do acidente da navegação: encalhe de mercante estrangeiro durante navegação no canal de acesso ao terminal de Contêineres-TECON, porto do Rio de Janeiro, baía de Guanabara, município do Rio de Janeiro, RJ. Sem danos materiais e sem registro de acidentes pessoais ou poluição ao meio ambiente hídrico; b) quanto à causa determinante: erro de navegação; e c) decisão: julgar 


\begin{abstract}
procedente a representação da Douta Procuradoria Especial da Marinha (fls. 121 a 132) e, considerando o acidente da navegação, previsto no art. 14, letra "a" da Lei no 2.180/54 e suas consequências, como decorrente das condutas imprudente de Luiz Felippe Vieira Pereira, na condição de prático e negligente do CLC Conyo Ivanov Conev, este na condição de então comandante, ambos do N/M “WESTFALIA EXPRESS", condenar o $1^{\circ}$ à pena de multa no valor de R\$ 50o,oo(quinhentos reais), prevista no inciso VII e o $2^{\circ}$ à pena de repreensão, prevista no inciso I, ambos do art. $121 \mathrm{c} / \mathrm{c}$ os arts. 124, incisos I e IX e 127, todos da Lei oㅡ 2.180/54, com redação alterada pela Lei no 8.969/94.
\end{abstract}

Desta forma, ao existir a condenação em sede de Tribunal Marítimo com o reconhecimento da culpa pelo comandante automaticamente estaria descaracterizado um dos elementos necessários para a configuração da avaria grossa, qual seja a razoabilidade do ato.

Isso, pois, a avaria grossa resta configurada quando uma expedição marítima está sob risco de um perigo iminente e real e o capitão, no intuito de salvar o navio e a carga sob sua guarda, determina sacrifício de parte da carga ou do próprio navio ou seus acessórios ou, ainda, determina mudança de rota, aqueles interesses de bordo que tiverem perdas em proveito dos demais devem ter ser seu patrimônio recomposto por meio de um rateio especial (SILVA FILHO, 2015, p. 454).

Como visto, de acordo com a Regra "Paramount" (RYA), em nenhuma hipótese haverá qualquer admissão por sacrifício ou despesa, a menos que razoavelmente feitos ou incorridos, onde razoabilidade do ato é elemento intrínseco caracterizador da avaria grossa.

Ou seja, quando a avaria grossa resultar de acidente ou fato da navegação, caberá ao Tribunal Marítimo determinar se, no caso concreto, houve culpa dos envolvidos, através de processo administrativo próprio, e caso essa seja comprovada, restará afastado o elemento necessário para a configuração da avaria grossa, qual seja a razoabilidade da conduta.

Desta forma, o processo no Tribunal Marítimo tem o condão de elidir a razoabilidade da conduta, afastando a possibilidade de caracterização e reconhecimento da avaria grossa.

Destaca-se que quando se discutir em juízo questão decorrente de acidentes e fatos da navegação da competência do Tribunal Marítimo haverá suspensão do processo (Art. 313, VII, CPC/15), fato esse que demonstra nitidamente a importância da atuação do tribunal em comento em questões afetas às avarias grossas.

\title{
CONCLUSÃO
}

A atuação do Tribunal Marítimo não fere o acesso ao Poder Judiciário, órgão responsável pela atividade jurisdicional, posto que aquele atua de forma conjunta, com o intuito de assessoramento. Desta forma, através de uma corte altamente especializada, se pode processar a devida apuração de fatos específicos ligados à navegação.

O Tribunal Marítimo além de ser órgão auxiliar do Poder Judiciário, nas matérias de sua competência, julga com um elevado grau de competência técnica, vez que nem 
mesmo o Judiciário está preparado ou aparelhado para decidir conflitos de natureza especial, bastando para tanto verificarmos a composição do colegiado do Tribunal Marítimo, suas prerrogativas e sua estrutura.

Restou demonstrado que a competência do Tribunal Marítimo é de julgar os acidentes e os fatos, não apenas os descritos na Lei $\mathrm{n}^{\mathrm{o}} \mathbf{2 . 1 8 0 / 1 9 5 4}$, considerando que o referido diploma legal estabelece um rol meramente exemplificativo.

Explanou-se que regulação de avaria grossa encontra ligação direta com o Tribunal Marítimo, principalmente, no que concerne ao afastamento de elementos impensáveis ao reconhecimento da avaria grossa.

Inicialmente, mesmo se tratando de uma hipótese legal em desuso, que nunca foi aplicada pelo Tribunal Marítimo, de acordo com o art. 17, alínea f, da Lei $n^{0}$ 2.18o/1954, na apuração da responsabilidade por fatos e acidentes da navegação, cabe ao Tribunal Marítimo investigar os requisitos que autorizam a regulação estão presentes, nos casos de acidentes ou fato da navegação de que possa resultar a classificação de danos e despesas como avaria grossa ou comum.

E, principalmente, considerando que a responsabilidade administrativa marítima segue a teoria da responsabilidade subjetiva, devendo-se perquirir o dolo ou a culpa. Portanto, ao existir a condenação em sede de Tribunal Marítimo com o reconhecimento da culpa pelo comandante automaticamente estará descaracterizado um dos elementos necessários para a configuração da avaria grossa, qual seja a razoabilidade do ato.

Ou seja, quando a avaria grossa resultar de acidente ou fato da navegação, caberá ao Tribunal Marítimo determinar se, no caso concreto, houve culpa dos envolvidos, através de processo administrativo próprio, e caso essa seja comprovada, restará afastado o elemento necessário para a configuração da avaria grossa, qual seja a razoabilidade da conduta.

Desta forma, o processo no Tribunal Marítimo tem o condão de elidir a razoabilidade da conduta, afastando a possibilidade de caracterização e reconhecimento da avaria grossa.

\section{REFERENNCIAS}

CARNEIRO, Athos Gusmão. Jurisdição e competência. 11 ed. São Paulo: Saraiva, 2001.

CARNELUTTI, Francesco. Sistema di diritto processuale civile. Padova: Cedam, 1936. v. 1.

CAMPOS, Ingrid Zanella Andrade. Direito constitucional marítimo. Curitiba: Juruá, 2001.

A responsabilidade do afretador não armador. Disponível em: < http:// www.congressomaritimosantos.com.br/palestras_documentos.php >. Acesso em: 21 out. 2014. 
O papel do tribunal marítimo da defesa do meio ambiente. In III WorkShop do Tribunal Marítimo (o9/10/2013). Disponível em: < https://www.mar.mil.br/tm/ download/palestra_workshopIII/workshopIII_ingrid_zanella.pdf $>$. Acesso em: 21 out. 2014 .

FARIA, José Eduardo. Direito e justiça no século XXI: a crise da justiça no Brasil. Colóquio Internacional - Direito e Justiça no século XXI. Coimbra, 29 to 31 may. 2003.

GOMES, Luiz Flávio; VIGO, Luis Rodolfo. Do Estado de direito constitucional e transconstitucional: riscos e precauções (navegando pelas ondas evolutivas do Estado e da justiça). São Paulo: Premier Máxima, 2008.

MARTINS, Eliane Maria Octaviano; MATUSALÉM, Gonçalves Pimenta. Direito marítimo: Reflexões Doutrinárias. Rio de Janeiro: Lumen Juris, 2015.

. Curso de direito marítimo. 3 ed. Volume I. Barueri, SP: Manole, 2008.

MILARÉ, Édis. Direito do ambiente: a gestão ambiental em foco. Doutrina, jurisprudência, glossário. 7. Ed. rev., atual. e reform. São Paulo: Editora Revista dos Tribunais, 2011.

MARTÍNEZ, Ignacio Arroyo. Compendio de derecho marítimo. $3^{\underline{0}}$ Edición. Madrid: Editorial Tecnos, 2009.

NEVES, Marcelo. Transconstitucionalismo. São Paulo: Tese apresentada ao concurso para o provimento do cargo de professor titular na área de direito constitucional, junto ao Departamento de Direito do Estado da Faculdade de Direito da Universidade de São Paulo, 2009.

PORTO, Marcos Maia. Portos e o desenvolvimento. São Paulo: Lex Editora, 2006.

SILVA FILHO, Nelson Cavalcante. Ararias e Arribadas. In COELHO, Fábio Ulhoa. Tratado de direito comercial. Volume 7: falência e recuperação de empresa e direito marítimo. Sao Paulo: Saraiva, 2015.

TEUBNER, Gunther. O Direito como Sistema Autopoiético. Lisboa: Fundação Calouste Gulbenkian, 1989.

The King's many bodies: the self-deconstruction of Law's Hierarchy. Law \& Society Review, Volume 31, Number 4 (1997). By the Law \& Society Association. 